\title{
Monitoring Resistance to SDHI Fungicides in Botrytis cinerea From Strawberry Fields
}

Meng-Jun Hu, Department of Agricultural and Environmental Sciences, Clemson University, Clemson, SC 29634; Dolores Fernández-Ortuño,
Instituto de Hortofruticultura Subtropical y Mediterránea "La Mayora"-Universidad de Málaga-Consejo Superior de Investigaciones Científicas
(IHSM-UMA-CSIC), Departamento de Microbiología, Campus de Teatinos, 29071 Málaga, Spain; and Guido Schnabel, Department of Agricultural and Environmental Sciences, Clemson University

\begin{abstract}
Hu, M.-J., Fernández-Ortuño, D., and Schnabel, G. 2016. Monitoring resistance to SDHI fungicides in Botrytis cinerea from strawberry fields. Plant Dis. 100:959-965.

Succinate dehydrogenase inhibitor (SDHI) fungicides have been used to control gray mold of strawberry for more than a decade, and selection for resistance in the causal agent Botrytis cinerea has become a threat to producers. In total, $2,570 \mathrm{~B}$. cinerea isolates were collected from strawberry fields in the eastern United States across three seasons and their sensitivity to the SDHI materials boscalid, fluopyram, fluxapyroxad, and penthiopyrad was assessed. Assays were based on visual assessment of presence or absence of mycelial growth on media amended with discriminatory fungicide doses to distinguish sensitive from resistant isolates, respectively. Overall frequencies of isolates resistant to boscalid, fluopyram, fluxapyroxad, and penthiopyrad increased over the 3 years to $30.0,1.0,5.5$, and $7.4 \%$, respectively. Four resistance patterns, designated A, B, C, or D, were found. Pattern A isolates were resistant to boscalid with the allele H272R at locus

$s d h B$; pattern B isolates were resistant to boscalid and penthiopyrad with the allele $\mathrm{H} 272 \mathrm{R}$ or $\mathrm{H} 272 \mathrm{Y}$ at locus $s d h B$; pattern C isolates were resistant to boscalid, fluxapyroxad, and penthiopyrad with the allele $\mathrm{H} 272 \mathrm{Y}$ at locus $s d h B$; and pattern D isolates were resistant to boscalid, fluopyram, fluxapyroxad, and penthiopyrad with alleles $\mathrm{P} 225 \mathrm{~F}$ or $\mathrm{N} 230 \mathrm{I}$ at locus $s d h B$. Isolates with alleles H272Y, N230I, or P225F were sensitive to a new SDHI, benzovindiflupyr, with mean effective dose that inhibits $50 \%$ of mycelial growth values of less than $0.5 \mu \mathrm{g} / \mathrm{ml}$ for each genotype, suggesting that this fungicide may be useful for resistance management. Our data show an increase of $B$. cinerea isolates resistant to SDHI fungicides over three consecutive production seasons. Resistance management practices must be implemented for the sustained efficacy of SDHI fungicides against gray mold of strawberry.
\end{abstract}

Botrytis cinerea Pers., the causal agent of gray mold fruit rot disease, is one of the most important pathogens of strawberry (Fragaria $\times$ ananassa) worldwide. For plasticulture production, the fungus can enter the production field with annual nursery stock in the form of latent infections in leaf or crown tissue, from plant material adjacent to the strawberry field (Schnabel et al. 2015), or from spores produced in overwintering plant debris (Sutton 1998). Losses resulting from gray mold are especially severe during persistent wetness at moderate temperatures. Symptoms develop not only during the crop growing season but also after harvest and during storage and transit (Sutton 1998).

Cultural methods such as accelerating drying time within the plant canopy and reduction of inoculum density can reduce gray mold; however, management of this disease still relies on fungicides. $B$. cinerea is a classical high-risk pathogen with respect to the development of fungicide resistance (Leroux et al. 2002) and, thus, management of this risk is an important aspect of achieving sustainable strawberry production. Recent studies in the southeastern United States have documented resistance in B. cinerea to all single-site mode of action fungicide classes registered for gray mold of strawberry (Fernández-Ortuño et al. 2012, 2014; Grabke et al. 2013, 2014; Li et al. 2014).

New generations of succinate dehydrogenase inhibitor (SDHI) fungicides have been developed in recent years (Sierotzki and Scalliet 2013). To date, in total, 18 commercial SDHI fungicides belonging to

Corresponding author: G. Schnabel; E-mail: SCHNABE@clemson.edu

M.-J. Hu and D. Fernández-Ortuño contributed equally to this work.

Accepted for publication 7 December 2015.

http://dx.doi.org/10.1094/PDIS-10-15-1210-RE

(C) 2016 The American Phytopathological Society eight different chemical subgroups are available for control of fungal plant pathogens. SDHI fungicides prevent mitochondrial respiration by inhibiting the activity of mitochondrial respiratory complex II that comprises a flavoprotein (SdhA), an iron-sulfur protein (SdhB), and two membrane-anchored proteins (SdhC and SdhD) (Hägerhäll 1997). SDHI fungicides show no cross-resistance with other chemical classes and, therefore, are useful for managing fungicide resistance and optimizing disease control (Avenot et al. 2008a; Veloukas and Karaoglanidis 2012; Zhang et al. 2007). The first SDHI fungicide, carboxin, was registered in 1966 and controlled mainly basidiomycetes (Motoba et al. 1988; Ulrich and Mathre 1972; Zhang et al. 2009). Newer-generation SDHI fungicides include boscalid, penthiopyrad, and fluopyram, which are characterized by a broader spectrum of fungal activity (Yanase et al. 2007). Benzovindiflupyr represents the latest SDHI and controls rusts, many different leaf spots, apple scab, powdery mildew, and Rhizoctonia spp. and will be available for use on wheat, corn, cucurbit and fruiting vegetables, grape, peanut, pome fruit, potato, and soybean in the United States.

SDHI fungicides are classified as medium to high risk for resistance development due to the specificity of their mode of action and their widespread use. Resistance to carboxin, flutolanil, and boscalid was reported shortly after their registration, with several different mutations in one of the subunits $(\mathrm{B}, \mathrm{C}$, or $\mathrm{D})$ of the $\mathrm{SDH}$ complex found to be associated with resistance (Avenot et al. 2008b; Broomfield and Hargreaves 1992; Georgopoulos et al. 1972; Gunatilleke et al. 1975; Ito et al. 2004; Matsson et al. 1998; Skinner et al. 1998). With regard to B. cinerea, replacement of histidine by either tyrosine (allele H272Y) or arginine (allele H272R) at codon 272 of the $s d h B$ locus was observed most frequently in field isolates (Fernández-Ortuño et al. 2012; Leroux et al. 2010; Veloukas et al. 2011; Yin et al. 2011). A third mutation at the same codon of $s d h B$, allele $\mathrm{H} 272 \mathrm{~L}$, has also been detected at low frequencies (Leroux et al. 2010). In addition to variations at position 272, mutations giving rise to alleles P225F, P225T, P225L, P225H, and N230I have also been reported in association with resistance to SDHI in $s d h B$ 
(Amiri et al. 2014; Esterio et al. 2015; Leroux et al. 2010; Veloukas et al. 2011, 2013). Only one mutation associated with SDHI resistance was detected in the $s d h D$ subunit of $B$. cinerea, leading to a substitution of histidine by arginine at codon 132 (allele H132R; Leroux et al. 2010).

Currently, three SDHI fungicides (boscalid, fluxapyroxad, and penthiopyrad) are available for gray mold control in strawberry in the United States, and fluopyram and benzovindiflupyr may be registered in the near future. The objectives of the present study were to (i) determine the frequency of resistance to fluopyram, fluxapyroxad, penthiopyrad, and boscalid in B. cinerea sampled from strawberry fields over three seasons; (ii) determine resistance patterns to SDHI fungicides and their molecular basis and prevalence; and (iii) evaluate whether existing SDHI resistance alleles influence the sensitivity of the gray mold pathogen to benzovindiflupyr.

\section{Materials and Methods}

Fungal isolates. Twenty-five single-spore isolates of $B$. cinerea previously characterized for their sensitivity to boscalid and associated alleles in $s d h B$ (Fernández-Ortuño et al. 2012) were used to determine discriminatory doses for fluopyram, fluxapyroxad, and penthiopyrad. These isolates plus one additional isolate (77-7) that was added to show all resistance pattern-allele combinations found in this study are displayed in Table 1 . In all, 23 of these isolates ( 8 sensitive and 15 resistant to boscalid with the H272R and H272Y alleles of $s d h B$ ) were collected previously from strawberry fruit originating from different locations (High Point, Mooresville, and Shelby) in North Carolina and South Carolina (Fernández-Ortuño et al. 2012). The remaining two $B$. cinerea isolates (12-255 and 12-355) were provided by Dr. Natalia Perez (University of Florida, Wimauma). They were resistant to boscalid, fluopyram, fluxapyroxad, and penthiopyrad and carried the N230I (12-255) and P225F (12-355) alleles in $s d h B$.
For monitoring SDHI resistance, B. cinerea isolates were collected from strawberry fields as described previously (Fernández-Ortuño et al. 2014). Flowers were collected randomly from fields that had not yet revealed gray mold symptoms. Fruit symptomatic for gray mold were collected only from operations and fields where gray mold was considered a problem by the producer. Each isolate came from a different flower or fruit. Ten isolates were collected from a single field and no more than two sets of 10 isolates per farm operation and per year were included in the study to ensure that no single operation was overrepresented. To obtain conidia from blossom samples, 20 to 40 strawberry blossoms with a degenerated, black torus (likely caused by freeze damage) were obtained from each strawberry field tested. Flowers were shipped in zip lock bags. After petals were removed, the blossoms were surface sterilized with $10 \%$ bleach for $1 \mathrm{~min}$, rinsed with sterile water for $1 \mathrm{~min}$, and allowed to air dry for $5 \mathrm{~min}$. Then, the blossoms were placed into petri dishes $(15 \mathrm{~cm}$ in diameter) containing sterile filter paper and $2 \mathrm{ml}$ of sterile water. The blossoms were kept at $22^{\circ} \mathrm{C}$ for 2 to 4 days, after which many became symptomatic for gray mold. During the first $24 \mathrm{~h}$, the dishes were kept in sealed plastic bags to keep the relative humidity at 98 to $100 \%$. For fruit samples, 10 to 12 individual strawberry fruit with small (young) gray mold lesions were obtained from commercial fields; each fruit came from a different plant, with at least five buffer plants between sampled plants. Conidia were collected in the field using individually wrapped sterile cotton swabs (Fisher Scientific). The cotton tip was rubbed gently against the youngest area of sporulation (periphery of the lesion) of a fruit to capture conidia. The white cotton tip turned from pure white to lightly gray, indicating that sufficient conidia were collected; then, the swab was returned to its wrapper, placed in a zip lock bag, and returned to the lab for processing. Fungicide sensitivity of the bulk conidial isolates was defined using a novel mycelial growth assay.

Table 1. Name, origin, year of isolation, and succinate dehydrogenase inhibitor (SDHI) resistance profile of Botrytis cinerea isolates collected from strawberry prior to the multiyear resistance monitoring study

\begin{tabular}{|c|c|c|c|c|c|c|c|c|}
\hline \multirow[b]{2}{*}{ Name $^{x}$} & \multirow[b]{2}{*}{ State of origin } & \multirow[b]{2}{*}{ Year $^{\mathbf{y}}$} & \multirow[b]{2}{*}{$\begin{array}{l}\text { SdhB } \\
\text { allele }\end{array}$} & \multicolumn{4}{|c|}{ Presence (+) or absence (-) of mycelium growthw } & \multirow[b]{2}{*}{ Pattern $^{2}$} \\
\hline & & & & $\begin{array}{l}\text { Boscalid } \\
(75 \mu \mathrm{g} / \mathrm{ml})\end{array}$ & $\begin{array}{c}\text { Fluopyram } \\
(10 \mu \mathrm{g} / \mathrm{ml})\end{array}$ & $\begin{array}{l}\text { Fluxapyroxad } \\
\qquad(5 \mu \mathrm{g} / \mathrm{ml})\end{array}$ & $\begin{array}{c}\text { Penthiopyrad } \\
(5 \mu \mathrm{g} / \mathrm{ml})\end{array}$ & \\
\hline FLOR2 & South Carolina & 2011 & $\mathrm{H} 272$ & - & - & - & - & N/A \\
\hline GIK1 & South Carolina & 2011 & $\mathrm{H} 272$ & - & - & - & - & N/A \\
\hline HP1 & North Carolina & 2011 & $\mathrm{H} 272$ & - & - & - & - & N/A \\
\hline HP34 & North Carolina & 2011 & $\mathrm{H} 272$ & - & - & - & - & N/A \\
\hline MOD5 & South Carolina & 2011 & $\mathrm{H} 272$ & - & - & - & - & N/A \\
\hline MV1 & North Carolina & 2011 & $\mathrm{H} 272$ & - & - & - & - & N/A \\
\hline WIC1 & South Carolina & 2011 & $\mathrm{H} 272$ & - & - & - & - & N/A \\
\hline WIC19 & South Carolina & 2011 & $\mathrm{H} 272$ & - & - & - & - & N/A \\
\hline FLOR6 & South Carolina & 2011 & $\mathrm{H} 272 \mathrm{R}$ & + & - & - & - & A \\
\hline GIK3 & South Carolina & 2011 & $\mathrm{H} 272 \mathrm{R}$ & + & - & - & - & A \\
\hline GIK10 & South Carolina & 2011 & $\mathrm{H} 272 \mathrm{R}$ & + & - & - & - & A \\
\hline HP16 & North Carolina & 2011 & $\mathrm{H} 272 \mathrm{R}$ & + & - & - & - & A \\
\hline MOD13 & South Carolina & 2011 & $\mathrm{H} 272 \mathrm{R}$ & + & - & - & - & A \\
\hline SBY11 & North Carolina & 2011 & $\mathrm{H} 272 \mathrm{R}$ & + & - & - & - & A \\
\hline SBY19 & North Carolina & 2011 & $\mathrm{H} 272 \mathrm{R}$ & + & - & - & - & A \\
\hline WIC7 & South Carolina & 2011 & $\mathrm{H} 272 \mathrm{R}$ & + & - & - & - & A \\
\hline $77-7$ & Georgia & 2014 & $\mathrm{H} 272 \mathrm{R}$ & + & - & - & + & $\mathrm{B}$ \\
\hline SPD4 & Georgia & 2010 & $\mathrm{H} 272 \mathrm{Y}$ & + & - & - & + & B \\
\hline GIK17 & South Carolina & 2011 & $\mathrm{H} 272 \mathrm{Y}$ & + & - & + & + & $\mathrm{C}$ \\
\hline GIK20 & South Carolina & 2011 & $\mathrm{H} 272 \mathrm{Y}$ & + & - & + & + & $\mathrm{C}$ \\
\hline KUD3 & South Carolina & 2011 & $\mathrm{H} 272 \mathrm{Y}$ & + & - & + & + & $\mathrm{C}$ \\
\hline KUD14 & South Carolina & 2011 & $\mathrm{H} 272 \mathrm{Y}$ & + & - & + & + & $\mathrm{C}$ \\
\hline MOD20 & South Carolina & 2011 & $\mathrm{H} 272 \mathrm{Y}$ & + & - & + & + & $\mathrm{C}$ \\
\hline MV11 & North Carolina & 2011 & $\mathrm{H} 272 \mathrm{Y}$ & + & - & + & + & $\mathrm{C}$ \\
\hline $12-255$ & Florida & N/A & N230I & + & + & + & + & $\mathrm{D}$ \\
\hline $12-355$ & Florida & N/A & $\mathrm{P} 225 \mathrm{~F}$ & + & + & + & + & $\mathrm{D}$ \\
\hline
\end{tabular}


Between the 2011-12 and 2014-15 strawberry seasons, 2,570 $B$. cinerea isolates were collected from 257 fields in 12 states (on average, 10 isolates per field), including Alabama (10 isolates), Arkansas (120 isolates), Connecticut (50 isolates), Georgia (110 isolates), Michigan (10 isolates), Maryland (400 isolates), Missouri (10 isolates), North Carolina (450 isolates), Ohio (10 isolates), Pennsylvania (30 isolates), South Carolina (1,040 isolates), and Virginia (330 isolates). Over seasons of sampling, isolates did not necessarily come from the same farm each season; however, isolates from Maryland and South Carolina were generally from the same farms.

In total, 30 isolates were used to determine the sensitivity to benzovindiflupyr. They were collected over the course of this 3-year study, with the exception of isolate $12-355$ containing allele P225F in $s d h B$, which was obtained from a collaborator in Florida (Table 1). The sensitive isolates and isolates representing different alleles were collected in different years and different locations to minimize collection bias.

Selection of discriminatory doses and determination of resistance to SDHI fungicides. Commercial formulations of boscalid (Endura fungicide, 70\% [wt/wt]; BASF Corporation), fluopyram (Luna Privilege fungicide; Bayer CropScience), fluxapyroxad (Xemium; BASF Corporation), and penthiopyrad (Fontelis; DuPont Crop Protection) were used to determine fungicide resistance profiles in $B$. cinerea isolates. For conidia production, the 25 isolates used for discriminatory dose determination were grown on potato dextrose agar medium (PDA; Difco Laboratories) in 9-cm-diameter petri dishes for 10 days at $22^{\circ} \mathrm{C}$, with 14-h intervals of fluorescent light and darkness.

The discriminatory concentration for boscalid was determined previously (Fernández-Ortuño et al. 2014). To determine discriminatory doses for fluopyram, fluxapyroxad, or penthiopyrad, mycelial growth of the 25 representative $B$. cinerea isolates described above was evaluated on $0.5 \%$ yeast extract agar (YEA) and $1 \%$ yeast bacto acetate agar (YBA) amended with each material at 10,5 , and $1 \mu \mathrm{g} / \mathrm{ml}$ (Fernández-Ortuño et al. 2014; Stammler and Speakman 2006). Tests were conducted in wells ( $15 \mathrm{~mm}$ in diameter) of 24-well plates ( 6 by 4 wells, 12.5 by 8.5 by $2 \mathrm{~cm}$; Thermo Fischer Scientific). Conidia were collected from 10-day-old, actively growing colonies using a cotton swab by gently touching a sporulating area of the colony until the cotton was lightly gray. Conidia were transferred from the cotton to each well using a sterile wooden toothpick by stabbing the gray area of the cotton and slightly touching the top of the center of each well. Inoculated plates were incubated at $22^{\circ} \mathrm{C}$ for 4 days. Resistant isolates were distinguished from sensitive isolates based on presence (resistant isolates) or absence (sensitive isolates) of mycelial growth on fungicide-amended medium. Isolates resistant to SDHI fungicides were capable of growing at the discriminatory dose applied but isolates sensitive to SDHI fungicides were completely inhibited in growth. The experiment was repeated three times. For the 3-year monitoring study, the same 24-well plates described above were used. The monitoring was conducted using YBA medium amended with boscalid, fluopyram, fluxapyroxad, and penthiopyrad at $75,10,5$, and $5 \mu \mathrm{g} / \mathrm{ml}$ (Table 1).

DNA extraction from SDHI-resistant $B$. cinerea and PCR amplification of $\boldsymbol{s} \boldsymbol{d h} \boldsymbol{B}$ alleles. Representative isolates belonging to each SDHI resistance pattern (see below) were chosen randomly from different locations for sequencing. Isolates of $B$. cinerea were cultured on PDA plates at $22^{\circ} \mathrm{C}$. Aerial mycelia and conidia were collected using a stainless spatula and placed into a 1.5-ml Eppendorf tube filled with $0.5 \mathrm{ml}$ of extraction buffer (1 M KCL, $100 \mathrm{mM}$ Tris-HCL, and $10 \mathrm{mM}$ EDTA). Genomic DNA was then extracted and purified according to Chi et al. (2009). The iron-sulfur protein (SdhB) target gene of SDHI fungicides was amplified using primer pair IpBcBeg (5'-CCACTCCTCCATAATGGCTGCTCTCCGC-3') and IpBcEnd2 (5'-CTCATCAAGCCCCCTCATTGATATC-3') (Leroux et al. 2010). Briefly, PCR assays were carried out in an iCycler Thermal Cycler (T100; Bio-Rad Laboratories Inc.) in a final volume of $50 \mu \mathrm{l}$ containing 50 to $100 \mathrm{ng}$ of fungal genomic DNA, $2.5 \mathrm{mM} \mathrm{dNTP \text {, }}$ 10 pmol each primer, $5 \mu$ l of $10 \times$ Thermo Pol Buffer, and $0.25 \mu l$ of Taq DNA polymerase (New England Biolabs). PCR products were separated in ethidium bromide-stained $1 \%(\mathrm{wt} / \mathrm{vol})$ agarose gels
(Thermo Scientific), run in $1 \times$ Tris-Borate-EDTA buffer, and exposed to UV light to visualize DNA fragments. $s d h B$ gene PCR products were purified using the ExoSAP-IT PCR purification kit (USB Corporation) following manufacturer's instructions and sequenced in both directions at the Clemson University Genomics Institute.

Sensitivity of $B$. cinerea from strawberry to benzovindiflupyr. The sensitivity to benzovindiflupyr ( $97 \%$ technical grade provided by Syngenta Crop Protection) was investigated for 30 isolates ( 8 sensitive and 22 resistant to SDHI fungicides, with different nucleotide mutations in the $s d h B$ gene) was evaluated by determining the effective dose that inhibits $50 \%$ of mycelial growth ( $\mathrm{EC}_{50}$ values). Benzovindiflupyr was dissolved in dimethyl sulfoxide to prepare stock solutions. A microtiter assay was used to determine sensitivity of $B$. cinerea isolates to benzovindiflupyr as described previously, with some slight modifications (Stammler and Speakman 2006). B. cinerea spores were gently dislodged using sterile plastic inoculation loops, and the loops were dipped in $3 \mathrm{ml}$ of double-concentrated YBA medium ( $20 \mathrm{~g}$ of yeast extract, $20 \mathrm{~g}$ of Bacto peptone, and $40 \mathrm{~g}$ of sodium acetate in 1 liter of sterile deionized water). The resulting suspension was filtered through two layers of cheesecloth, and the suspension was adjusted with fresh YBA to a spore density of $2 \times$ $10^{4} \mathrm{ml}^{-1}$. Dilutions of benzovindiflupyr were prepared in sterile deionized water immediately before mixing with the spore suspensions. Then, $50 \mu \mathrm{l}$ of fungicide solution and $50 \mu \mathrm{l}$ of spore suspension were mixed in 96-well microtiter plates. The following final concentrations were used in the microtiter assay: active ingredient of benzovindiflupyr at $0,0.02,0.05,0.1,0.2,0.5,1$, and $2 \mu \mathrm{g} / \mathrm{ml}$. For each isolate and benzovindiflupyr concentration, three replicate wells were used. The microtiter plates were put into plastic bags to avoid evaporation and incubated at $22^{\circ} \mathrm{C}$ in darkness. Three days after inoculation, the growth was measured in a spectrophotometer at absorbance at $600 \mathrm{~nm}$. The values for each fungicide concentration were corrected using the corresponding blanks. A linear regression analysis was performed to calculate the $\mathrm{EC}_{50}$ values for each isolate.

Statistical analysis. A $\chi^{2}$ test was used to determine whether the probability of resistance to a fungicide differed between seasons. If less than 10 isolates were represented in a season, the Fisher's exact test was conducted to verify the $\chi^{2}$ results. $\mathrm{EC}_{50}$ values of isolates possessing different $s d h B$ alleles for benzovindiflupyr were compared using Tukey's honestly significant difference test with $\alpha=0.05$. All of the statistical analyses were performed using $\mathrm{R}$ software (version 3.2.0; R Foundation for Statistical Computing).

\section{Results}

Determination of discriminatory concentrations and resistance profiles of isolates with different mutations in $\boldsymbol{s d h B}$. Isolates with known mutations in $s d h B$ that confer resistance to SDHI fungicides were grown on YEA and YBA with a single discriminatory dose of each fungicide. Visual assessment of mycelial growth was carried out 4 days after inoculation. Distinction between sensitive and resistant phenotypes was easier to assess visually on $1 \%$ YBA because the mycelium was denser compared with $0.5 \%$ YEA (data not shown). Fluopyram at $10 \mu \mathrm{g} / \mathrm{ml}$, fluxapyroxad at $5 \mu \mathrm{g} / \mathrm{ml}$, and penthiopyrad at $5 \mu \mathrm{g} / \mathrm{ml}$ clearly distinguish $\mathrm{S}$ from $\mathrm{R}$ isolates based on visual assessment (presence/absence of growth). In addition, boscalid at $75 \mu \mathrm{g} / \mathrm{ml}$ was used to distinguish sensitive from resistant isolates in the present study (Fernández-Ortuño et al. 2014). In accordance with previous studies (Amiri et al. 2014; Veloukas et al. 2013), different mutations in $s d h B$ conferred differential sensitivity to SDHI. Four resistance patterns were found in our 2010-11 collection represented by 8 sensitive, 8 H272R, 7 H272Y, 1 $\mathrm{P} 225 \mathrm{~F}$, and $1 \mathrm{~N} 230 \mathrm{I}$ isolates. Pattern A represented isolates resistant to boscalid; pattern $\mathrm{B}$ represented isolates resistant to boscalid and penthiopyrad; pattern $\mathrm{C}$ represented isolates resistant to boscalid, fluxapyroxad, and penthiopyrad; and pattern D represented isolates resistant to all four SDHI fungicides (Table 1). Pattern A was associated with the H272R mutation, patterns B and $\mathrm{C}$ with the H272Y mutation, and pattern D with the N230I and P225F mutations (Table 1). 
Three-year monitoring for resistance to SDHI fungicides boscalid, fluopyram, fluxapyroxad, and penthiopyrad. In 2012-13, the overall frequencies of $920 \mathrm{~B}$. cinerea isolates resistant to boscalid, fluxapyroxad, and penthiopyrad were 7.2, 2.5 , and $2.5 \%$, respectively. Resistance to fluopyram was not detected. In 2013-14, the frequencies of 920 isolates resistant to boscalid, fluopyram, fluxapyroxad, and penthiopyrad were 8.5, 0.4, 3.0, and 3.6\%, respectively (Fig. 1). In 2014-15 this distribution was $30.0,1.0,5.5$, and $7.4 \%$, respectively (Fig. 1). The majority of isolates used for resistance monitoring were from Maryland, North Carolina, and South Carolina (Table 2). With the exception of Alabama, Missouri, and Michigan, resistance
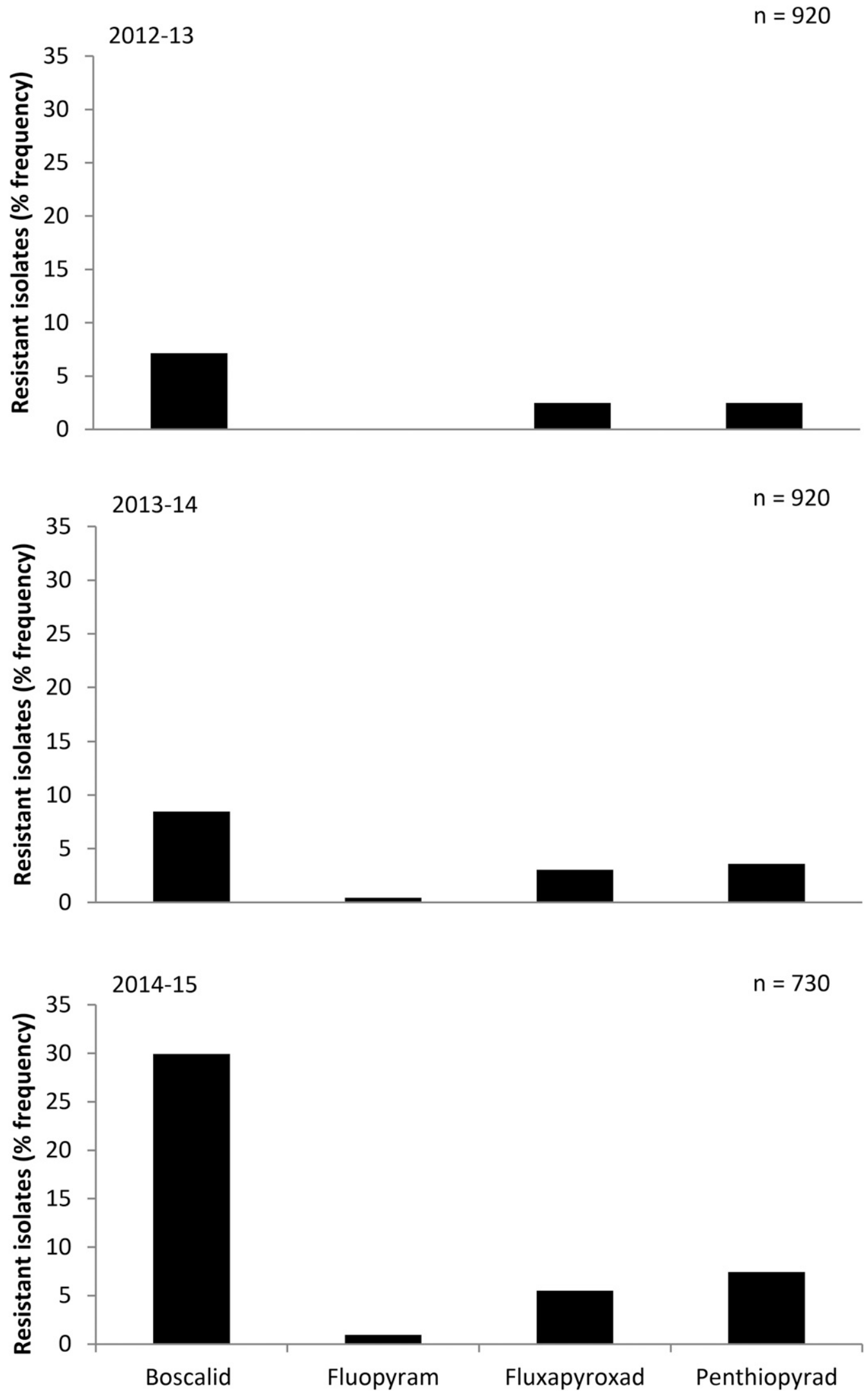

Fig. 1. Frequency of Botrytis cinerea isolates resistant to boscalid, fluopyram, fluxapyroxad, and penthiopyrad collected from strawberry fields in 12 states. 
to SDHI fungicides was found in every state. In total, 365 isolates with resistance to at least one SDHI fungicide were assigned SDHI resistance patterns based on presence or absence of mycelial growth on YBA medium with discriminatory doses of SDHI fungicides (Table 1). Pattern A was most commonly found and present in eight states, including Arkansas, Connecticut, Georgia, Maryland, North Carolina, Pennsylvania, South Carolina, and Virginia. Pattern $\mathrm{C}$ was the second most common pattern and was found in seven states, including Arkansas, Connecticut, Georgia, Maryland, North Carolina, South Carolina, and Virginia. Pattern B was found in six states, including Connecticut, Georgia, Maryland, North Carolina, South Carolina, and Virginia, and pattern D was found in three states, including Maryland, South Carolina, and Virginia (Table 2). The frequency of isolates belonging to patterns $\mathrm{A}, \mathrm{B}$, and D rose over 3 years according to a $\chi^{2}$ test $\left(\chi^{2}=193.7,21.1\right.$, and 8.8 , respectively; $P<0.01$; Table 2). The frequency of isolates belonging to pattern $\mathrm{C}$ did not statistically increase over time $\left(\chi^{2}=5.9, P=0.053\right)$. Patterns $\mathrm{A}$ and $\mathrm{C}$ were found in all three seasons but patterns $\mathrm{B}$ and D only emerged in seasons 2013-14 or 2014-15, depending

Table 2. Number and succinate dehydrogenase inhibitor (SDHI) resistance pattern of Botrytis cinerea isolates collected from 12 different states between 2012-13 and 2014-15 seasons

\begin{tabular}{|c|c|c|c|c|c|c|}
\hline \multirow[b]{2}{*}{ States } & \multirow[b]{2}{*}{ Year } & \multirow[b]{2}{*}{$N^{\mathbf{z}}$} & \multicolumn{4}{|c|}{$\begin{array}{l}\text { Number of isolates with SDHI } \\
\text { resistance pattern }(\%)^{\mathrm{y}}\end{array}$} \\
\hline & & & $\mathbf{A}$ & B & C & D \\
\hline \multirow[t]{3}{*}{ Alabama } & $2012-13$ & 0 & - & - & - & - \\
\hline & 2013-14 & 10 & 0 & 0 & 0 & 0 \\
\hline & $2014-15$ & 0 & - & - & - & - \\
\hline \multirow[t]{3}{*}{ Arkansas } & $2012-13$ & 50 & 0 & 0 & 0 & 0 \\
\hline & 2013-14 & 60 & $8(13.3)$ & 0 & $2(3.3)$ & 0 \\
\hline & 2014-15 & 10 & $3(30.0)$ & 0 & $1(10.0)$ & 0 \\
\hline \multirow[t]{3}{*}{ Connecticut } & 2012-13 & 10 & $2(20.0)$ & 0 & 0 & 0 \\
\hline & 2013-14 & 30 & $7(23.3)$ & $3(10)$ & $6(20.0)$ & 0 \\
\hline & $2014-15$ & 10 & $2(20.0)$ & 0 & $8(80.0)$ & 0 \\
\hline \multirow[t]{3}{*}{ Georgia } & $2012-13$ & 60 & $2(3.3)$ & 0 & 0 & 0 \\
\hline & 2013-14 & 50 & $6(12.0)$ & $2(4.0)$ & $1(2.0)$ & 0 \\
\hline & $2014-15$ & 0 & - & - & - & - \\
\hline \multirow[t]{3}{*}{ Maryland } & $2012-13$ & 150 & $12(8.0)$ & 0 & $7(4.7)$ & 0 \\
\hline & 2013-14 & 130 & $5(3.8)$ & 0 & $5(3.8)$ & $1(0.8)$ \\
\hline & $2014-15$ & 120 & $23(19.2)$ & $3(2.5)$ & 0 & 0 \\
\hline \multirow[t]{3}{*}{ Michigan } & $2012-13$ & 0 & - & - & - & - \\
\hline & 2013-14 & 0 & - & - & - & - \\
\hline & 2014-15 & 10 & 0 & 0 & 0 & 0 \\
\hline \multirow[t]{3}{*}{ Missouri } & $2012-13$ & 0 & - & - & - & - \\
\hline & 2013-14 & 10 & 0 & 0 & 0 & 0 \\
\hline & $2014-15$ & 0 & - & - & - & - \\
\hline \multirow[t]{3}{*}{ North Carolina } & $2012-13$ & 110 & $1(0.9)$ & 0 & $1(0.9)$ & 0 \\
\hline & 2013-14 & 190 & $1(0.5)$ & 0 & $1(0.5)$ & 0 \\
\hline & $2014-15$ & 150 & $42(28.0)$ & $1(0.7)$ & 0 & 0 \\
\hline \multirow[t]{3}{*}{ Ohio } & $2012-13$ & 0 & - & - & - & - \\
\hline & 2013-14 & 0 & - & - & - & - \\
\hline & $2014-15$ & 10 & $5(50.0)$ & 0 & 0 & 0 \\
\hline \multirow[t]{3}{*}{ Pennsylvania } & $2012-13$ & 20 & $4(20)$ & 0 & 0 & 0 \\
\hline & 2013-14 & 10 & $1(10)$ & 0 & 0 & 0 \\
\hline & 2014-15 & 0 & - & - & - & - \\
\hline \multirow[t]{3}{*}{ South Carolina } & 2012-13 & 340 & $13(3.8)$ & 0 & $10(2.9)$ & 0 \\
\hline & 2013-14 & 340 & $8(2.4)$ & 0 & $9(2.6)$ & $3(0.9)$ \\
\hline & $2014-15$ & 360 & $82(22.8)$ & $8(2.2)$ & $18(5.0)$ & $2(0.6)$ \\
\hline \multirow[t]{3}{*}{ Virginia } & $2012-13$ & 180 & $9(5.0)$ & 0 & $5(2.8)$ & 0 \\
\hline & 2013-14 & 90 & $9(10.0)$ & 0 & 0 & 0 \\
\hline & $2014-15$ & 60 & $12(20.0)$ & $2(3.3)$ & $5(8.3)$ & $5(8.3)$ \\
\hline \multirow[t]{3}{*}{ Total } & $2012-13$ & 920 & 43 (4.7) & 0 & $23(2.5)$ & 0 \\
\hline & 2013-14 & 920 & 45 (4.9) & $5(0.5)$ & $24(2.6)$ & $4(0.4)$ \\
\hline & $2014-15$ & 730 & $168(23.0)$ & $14(1.9)$ & $32(4.4)$ & $7(1.0)$ \\
\hline
\end{tabular}

y Pattern A = resistant to boscalid; pattern B = resistant to boscalid and penthiopyrad; pattern $\mathrm{C}=$ resistant to boscalid, fluxapyroxad, and penthiopyrad; and pattern $\mathrm{D}=$ isolates with resistance to all the fungicides.

${ }^{\mathrm{z}}$ Number of isolates. on the U.S. state of origin. Pattern A was found most frequently in all three seasons (Table 2).

SDHI resistance profiles in isolates collected over three consecutive growing seasons. In seasons 2012-13, 2013-14, and 2014-15, $43(4.7 \%), 45(4.9 \%)$, and $168(22.5 \%)$ isolates were identified with pattern A, respectively; $0(0 \%), 5(0.5 \%)$, and $14(1.9 \%)$ with pattern B; $23(2.5 \%), 24(2.6 \%)$, and $32(4.5 \%)$ with pattern C; and $0(0 \%)$, $4(0.4 \%)$, and $7(1.0 \%)$ with pattern D (Table 2). In total, 26, 6, 21, and 6 isolates from different states representing patterns A, B, C, and $\mathrm{D}$, respectively, were selected randomly during the monitoring process for $s d h B$ sequencing. The purpose was to verify the association of SDHI resistance pattern and $s d h B$ allele as determined with our 25 reference isolates (Table 1). Sequencing analysis revealed nucleotide variations in all isolates with resistance to at least one SDHI that corresponded to amino acid changes at position 272 or 230 in $s d h B$. As predicted based on our analysis of the 2010-11 collection (Table 1), the 26 pattern A isolates had the replacement of histidine by arginine at position 272 (H272R), the 21 pattern C isolates had the replacement of histidine by tyrosine at the same position $(\mathrm{H} 272 \mathrm{Y})$, and the 6 pattern $\mathrm{D}$ isolates had the replacement of asparagine by isoleucine at position 230 (N230I). Of the six pattern $\mathrm{B}$ representatives, five isolates possessed the $\mathrm{H} 272 \mathrm{Y}$ mutation and one isolate possessed the H272R mutation.

Sensitivity to benzovindiflupyr of $B$. cinerea isolates with $\mathrm{H} 272 \mathrm{R} / \mathrm{Y}, \mathbf{N 2 3 0 I}$, or P225F alleles in $\boldsymbol{s d h B}$. The $\mathrm{EC}_{50}$ values for benzovindiflupyr of wild-type isolates (isolates with allele $\mathrm{H} 272$ at $s d h B$ ) sensitive to SDHI and for isolates possessing mutant alleles $\mathrm{H} 272 \mathrm{R}, \mathrm{H} 272 \mathrm{Y}$, or N230I ranged from 0.01 to $0.07,0.01$ to 0.21 , 0.28 to 0.89 , and 0.15 to $0.44 \mu \mathrm{g} / \mathrm{ml}$, respectively. The $\mathrm{EC}_{50}$ value for benzovindiflupyr for the isolate possessing the $\mathrm{P} 225 \mathrm{~F}$ allele was $0.36 \mu \mathrm{g} / \mathrm{ml}$. Wild-type isolates exhibited the lowest mean (or highest sensitivity) of $\mathrm{EC}_{50}$ values $(0.02 \mu \mathrm{g} / \mathrm{ml})$, whereas isolates with the $\mathrm{H} 272 \mathrm{Y}$ mutation exhibited the highest mean (or lowest sensitivity) of $\mathrm{EC}_{50}$ values $(0.49 \mu \mathrm{g} / \mathrm{ml})$ for benzovindiflupyr (Table 3). It is noteworthy that the $\mathrm{EC}_{50}$ values of isolates possessing the H272Y allele were significantly higher than wild-type isolates and isolates possessing the $\mathrm{H} 272 \mathrm{R}$ allele (Table 3).

\section{Discussion}

Resistance to SDHI fungicide boscalid has been identified in $B$. cinerea from eastern strawberry fields (Fernández-Ortuño et al. 2014, 2015) but there are still good reasons to examine other SDHI for disease management. SDHI fungicides exhibit different intrinsic efficacy and vary in efficacy depending on the $s d h B$ mutant allele (Amiri et al. 2014; Ishii et al. 2011; Veloukas et al. 2013). During 3 years of monitoring, we identified four different SDHI resistance patterns, designated A, B, C, and D. Pattern A was the most prevalent pattern in each of the experimental years of this study, which is consistent with other studies (Amiri et al. 2014; Fernández-Ortuño et al. 2012; Veloukas et al. 2011). Boscalid has been used longer than any of the other SDHI and boscalid resistance was a component of all four patterns. The imbalanced frequency of SDHI resistance patterns may be because allele H272R emerged first and, thus, was subject to earlier selection. Another possibility is that genotypes with patterns B, $\mathrm{C}$, and D may be less fit and, thus, less competitive, which may have allowed pattern $\mathrm{A}$ isolates to become predominant among resistant

Table 3. Effective dose that inhibits $50 \%$ of mycelial growth values for benzovindiflupyr of Botrytis cinerea isolates with different $s d h B$ alleles

\begin{tabular}{lccc}
\hline Genotype & Number of isolates & Range $(\boldsymbol{\mu g} / \mathbf{m l})$ & Mean $(\boldsymbol{\mu g} / \mathbf{m l})^{\mathbf{z}}$ \\
\hline H272 (wild type) & 8 & $0.01-0.07$ & $0.02 \mathrm{~b}$ \\
H272R & 7 & $0.01-0.21$ & $0.10 \mathrm{~b}$ \\
H272Y & 7 & $0.28-0.89$ & $0.49 \mathrm{a}$ \\
N230I & 7 & $0.15-0.44$ & $0.34 \mathrm{ab}$ \\
P225F & 1 & $\ldots$ & $0.36 \mathrm{ab}$ \\
\hline
\end{tabular}

${ }^{z}$ Values within the same column followed by the same letters are not significantly different based on the analysis of Tukey's honestly significant difference test at $\alpha=0.05$. 
phenotypes in the absence of selection pressure. However, fitness data published thus far are inconclusive. For example, Lalève et al. (2014) found that growth, production of conidia and sclerotia, and pathogenicity were all impaired significantly in an H272R recombinant mutant compared with other $s d h B$ recombinant mutants, including H272Y, H272 L, N230I, P225F, and P225T. Amiri et al. (2014) studied field isolates and did not find evidence for fitness costs associated with the different mutations detected in the $s d h B$ in $B$. cinerea isolates from strawberry fields. The latter finding is also consistent with previous reports on other fungal plant pathogens (Avenot and Michailides 2007; Fraaije et al. 2012; Miyamoto et al. 2009; Scalliet et al. 2012). Similar to our study, H272R was found to be the predominant mutation in Greek strawberry populations (Veloukas et al. 2011). The authors suggest that this predominance to be rooted in differences in fitness of the mutated strains, their survival and competitive ability in the field, the fungicide spray schedules, and the application doses.

We observed a significant rise of pattern B over time $\left(\chi^{2}=21.15\right.$, $P<0.0001$ ), which is characterized by resistance to boscalid and penthiopyrad. The latter fungicide has been sold in the form of trade name Fontelis (DuPont) and has been used since 2012 for gray mold control. Most of the increase of pattern B was observed due to their emergence during the 2014-15 season in Connecticut, Maryland, and North Carolina. Pattern C is characterized by resistance to boscalid, penthiopyrad, and fluxapyroxad. The latter was registered in 2014 for gray mold control of strawberry and other crops in premixture with pyraclostrobin (Merivon; BASF Corporation). The statistically not significant rise of pattern $C$ in season $2014-15\left(\chi^{2}=5.89, P>0.05\right)$ was likely due to the introduction of Merivon and associated selection pressure by fluxapyroxad.

Similar to pattern B, SDHI pattern D emerged first during the 2013-14 season. During this time, it was found in strawberry fields of Maryland and South Carolina. A year later, we found pattern D again in South Carolina and, for the first time, in Virginia. This pattern is characterized by resistance to boscalid, penthiopyrad, fluxapyroxad, and fluopyram. As of 2015, fluopyram had not been registered and, thus, selection for pattern D was not linked to selection by fluopyram. Therefore, patterns $\mathrm{C}$ and $\mathrm{D}$ were selected by the same fungicides (boscalid, penthiopyrad, and fluxapyroxad), which suggests that the emergence of pattern D, represented by allele N230I, occurred later compared with pattern $\mathrm{C}$, represented by $\mathrm{H} 272 \mathrm{Y}$.

Generally, the patterns identified in this study were associated with a specific point mutation in the $s d h B$ gene, with one exception. Pattern A was associated with the H272R mutation, patterns B and $C$ with the H272Y mutation, and pattern D with either the N230I or P225F mutation. This is consistent with other studies reporting that different mutations in $s d h B$ confer differential activity spectra to SDHI fungicides in B. cinerea (Amiri et al. 2014; Veloukas et al. 2013). In this study, depending on the isolate, a specific point mutation was able to confer more than one pattern. Specifically, pattern B was identified primarily for isolates with the H272Y allele but also in one isolate with the $\mathrm{H} 272 \mathrm{R}$ allele. This is because $B$. cinerea isolates with a specific point mutation may reveal a range of $\mathrm{EC}_{50}$ values for a specific SDHI that was not captured by the discriminatory dose selected. $\mathrm{EC}_{50}$ values for penthiopyrad specifically may range from 0.21 to $4.18 \mu \mathrm{g} / \mathrm{ml}$ for isolates with the $\mathrm{H} 272 \mathrm{R}$ mutation and from 5.51 to $19.47 \mu \mathrm{g} / \mathrm{ml}$ for isolates with the $\mathrm{H} 272 \mathrm{Y}$ mutation (Amiri et al. 2014). Pattern $C$ was the second most frequent pattern found and, thus, H272Y may be the second most frequent mutation in our dataset. This mutation, along with H272R, was also commonly found in $B$. cinerea isolates from strawberry (Amiri et al. 2014; Fernández-Ortuño et al. 2012; Veloukas et al. 2011) and other fruit, including apple and grape (Leroux et al. 2010; Yin et al. 2011).

Benzovindiflupyr is the latest SDHI fungicide, which has not yet been registered and used commercially for gray mold control of strawberry in the United States. Benzovindiflupyr showed high fungicidal activity, with $\mathrm{EC}_{50}$ values less than $1 \mu \mathrm{g} / \mathrm{ml}$ for all genotypes tested (Table 3). This is in sharp contrast to $\mathrm{EC}_{50}$ values for most of the other SDHI. For example, the mean $\mathrm{EC}_{50}$ values for boscalid of isolates with any $s d h B$ mutation were greater than $100 \mu \mathrm{g} / \mathrm{ml}$ (Amiri et al. 2014). The same study showed that mean $\mathrm{EC}_{50}$ values for fluopyram were $1,0.5,10$, and $99 \mu \mathrm{g} / \mathrm{ml}$; for fluxapyroxad they were 1 , 10,10 , and $>100 \mu \mathrm{g} / \mathrm{ml}$; and for penthiopyrad they were $1,8,7$, and $13 \mu \mathrm{g} / \mathrm{ml}$ for isolates carrying mutations H272R, H272Y, N230I, and P225F, respectively (Amiri et al. 2014).

All SDHI fungicides belong to Fungicide Resistance Action Committee (FRAC) group 7 and, thus, should not be applied consecutively in a resistance management program. However, growers may choose to alternate different SDHI with other FRAC groups for improved disease management to take advantage of the different efficacy spectra in populations with multiple $s d h B$ alleles. This may, however, select more rapidly for patterns B, C, and D. Given the high risk for resistance development and the rise in resistance frequencies reported here, the total number of applications of SDHI fungicides per season should probably be further restricted to extend the life of this important chemical class of fungicides.

\section{Acknowledgments}

Technical Contribution Number 6395 of the Clemson University Experiment Station. This material is based upon work supported by NIFA/USDA under project number SC-1700501 and NIFA/USDA SCRI grant number 2014-51181-22377. D. Fernández-Ortuño has received funding from the Marie Curie COFUND programme U-Mobility, co-financed by the University of Malaga, the European Commission FP7 under GA Number 246550, and Ministerio de Economía y Competitividad (COFUND2013-40259). We thank P. K. Bryson, A. Grabke, and J. H. Yang for technical support

\section{Literature Cited}

Amiri, A., Heath, S. M., and Peres, N. A. 2014. Resistance to fluopyram, fluxapyroxad, and penthiopyrad in Botrytis cinerea from Strawberry. Plant Dis. 98:532-539.

Avenot, H. F., and Michailides, T. J. 2007. Resistance to boscalid fungicide in Alternaria alternata isolates from pistachio in California. Plant Dis. 91: $1345-1350$.

Avenot, H. F., Morgan, D. P., and Michailides, T. J. 2008a. Resistance to pyraclostrobin, boscalid and multiple resistance to Pristine ${ }^{\circledR}$ (pyraclostrobin + boscalid) fungicide in Alternaria alternata causing Alternaria late blight of pistachios in California. Plant Pathol. 57:135-140.

Avenot, H. F., Sellam, A., Karaoglanidis, G., and Michailides, T. J. 2008b. Characterization of mutations in the iron-sulphur subunit of succinate dehydrogenase correlating with boscalid resistance in Alternaria alternata from California Pistachio. Phytopathology 98:736-742.

Broomfield, P. L. E., and Hargreaves, J. A. 1992. A single amino-acid change in the iron-sulphur protein subunit of succinate dehydrogenase confers resistance to carboxin in Ustilago maydis. Curr. Genet. 22:117-121.

Chi, M.-H., Park, S.-Y., and Lee, Y.-H. 2009. A quick and safe method for fungal DNA extraction. Plant Pathol. J. 25:108-111.

Esterio, M., Araneda, M. J., Román, A., Pizarro, L., Copier, C., and Auger, J. 2015 First report of boscalid resistant Botrytis cinerea isolates carrying the mutations H272R, H272Y, P225L, and P225H from table grape in Chile. Plant Dis. 99: 891.

Fernández-Ortuño, D., Chen, F., and Schnabel, G. 2012. Resistance to pyraclostrobin and boscalid in Botrytis cinerea isolates from strawberry fields in the Carolinas. Plant Dis. 96:1198-1203.

Fernández-Ortuño, D., Grabke, A., Bryson, P. K., Amiri, A., Peres, N. A., and Schnabel, G. 2014. Fungicide resistance profiles in Botrytis cinerea from strawberry fields of seven Southern U.S. states. Plant Dis. 98:825-833.

Fernández-Ortuño, D., Grabke, A., Li, X., and Schnabel, G. 2015. Independent emergence of resistance to seven chemical classes of fungicides in Botrytis cinerea. Phytopathology 105:424-432.

Fraaije, B. A., Bayon, C., Atkins, S., Cools, H. J., Lucas, J. A., and Fraaije, M. W. 2012. Risk assessment studies on succinate dehydrogenase inhibitors, the new weapons in the battle to control Septoria leaf blotch in wheat. Mol. Plant Pathol. 13:263-275.

Georgopoulos, S., Alexandri, E., and Chrysayi, M. 1972. Genetic evidence for the action of oxathiin and thiazole derivatives on the succinic dehydrogenase system of Ustilago maydis mitochondria. J. Bacteriol. 110:809-817.

Grabke, A., Fernández-Ortuño, D., Amiri, A., Li, X., Peres, N. A., Smith, P., and Schnabel, G. 2014. Characterization of iprodione resistance in Botrytis cinerea from strawberry and blackberry. Phytopathology 104:396-402.

Grabke, A., Fernández-Ortuño, D., and Schnabel, G. 2013. Fenhexamid resistance in Botrytis cinerea from strawberry fields in the Carolinas is associated with four target gene mutations. Plant Dis. 97:271-276.

Gunatilleke, I., Arst, H., and Scazzocchio, C. 1975. Three genes determine the carboxin sensitivity of mitochondrial succinate oxidation in Aspergillus nidulans. Genet. Res. 26:297-305.

Hägerhäll, C. 1997. Succinate: Quinone oxidoreductases: Variations on a conserved theme. Biochim. Biophys. Acta. Bioenerg. 1320:107-141. 
Ishii, H., Miyamoto, T., Ushio, S., and Kakishima, M. 2011. Lack of crossresistance to a novel succinate dehydrogenase inhibitor, fluopyram, in highly boscalid-resistant isolates of Corynespora cassiicola and Podosphaera xanthii. Pest Manage. Sci. 67:474-482.

Ito, Y., Muraguchi, H., Seshime, Y., Oita, S., and Yanagi, S. O. 2004. Flutolanil and carboxin resistance in Coprinus cinereus conferred by a mutation in the cytochrome b (560) subunit of succinate dehydrogenase complex (complex II). Mol. Genet. Genomics 272:328-335.

Lalève, A., Fillinger, S., and Walker, A. S. 2014. Fitness measurement reveals contrasting costs in homologous recombinant mutants of Botrytis cinerea resistant to succinate dehydrogenase inhibitors. Fungal Genet. Biol. 67: 24-36.

Leroux, P., Fritz, R., Debieu, D., Albertini, C., Lanen, C., Bach, J., Gredt, M., and Chapeland, F. 2002. Mechanisms of resistance to fungicides in field strains of Botrytis cinerea. Pest Manage. Sci. 58:876-888.

Leroux, P., Gredt, M., Leroch, M., and Walker, A.-S. 2010. Exploring mechanisms of resistance to respiratory inhibitors in field strains of Botrytis cinerea, the causal agent of gray mold. Appl. Environ. Microbiol. 76:6615-6630.

Li, X., Fernández-Ortuño, D., Grabke, A., and Schnabel, G. 2014. Resistance to fludioxonil in Botrytis cinerea isolates from blackberry and strawberry. Phytopathology 104:724-732.

Matsson, M., Ackrell, B. A. C., Cochran, B., and Hederstedt, L. 1998. Carboxin resistance in Paracoccus denitrificans conferred by a mutation in the membrane-anchor domain of succinate: Quinone reductase (complex II). Arch. Microbiol. 170:27-37.

Miyamoto, T., Ishii, H., Seko, T., Kobori, S., and Tomita, Y. 2009. Occurrence of Corynespora cassiicola isolates resistant to boscalid on cucumber in Ibaraki Prefecture, Japan. Plant Pathol. 58:1144-1151.

Motoba, K., Uchida, M., and Tada, E. 1988. Mode of antifungal action and selectivity of flutolanil. Agric. Biol. Chem. 52:1445-1449.

Scalliet, G., Bowler, J., Luksch, T., Kirchhofer-Allan, L., Steinhauer, D., Ward, K., Niklaus, M., Verras, A., Csukai, M., Daina, A., and Fonné-Pfister, R. 2012. Mutagenesis and functional studies with succinate dehydrogenase inhibitors in the wheat pathogen Mycosphaerella graminicola. PLoS One 7:e35429.

Schnabel, G., Hu, M., and Fernández-Ortuño, D. 2015. Monitoring resistance by bioassay: Relating results to field use using culturing methods. Pages 281-293 in: Fungicide Resistance in Plant Pathogens. H. Ishii and D. W. Hollomon, eds. Springer, Tokyo, Heidelberg, New York, Dordrecht, London.
Sierotzki, H., and Scalliet, G. 2013. A review of current knowledge of resistance aspects for the next-generation succinate dehydrogenase inhibitor fungicides. Phytopathology 103:880-887.

Skinner, W., Bailey, A., Renwick, A., Keon, J., Gurr, S., and Hargreaves, J. 1998 A single amino-acid substitution in the iron-sulphur protein subunit of succinate dehydrogenase determines resistance to carboxin in Mycosphaerella graminicola. Curr. Genet. 34:393-398.

Stammler, G., and Speakman, J. 2006. Microtiter method to test the sensitivity of Botrytis cinerea to boscalid. J. Phytopathol. 154:508-510.

Sutton, J. C. 1998. Botrytis fruit rot (gray mold) and blossom blight. Page 28 in: Compendium of Strawberry Diseases. J. L. Maas, ed. American Phytopathological Society, St. Paul, MN.

Ulrich, J. T., and Mathre, D. E. 1972. Mode of action of oxathiin systemic fungicides V. Effect on electron transport system of Ustilago maydis and Saccharomyces cerevisiae. J. Bacteriol. 110:628-632.

Veloukas, T., and Karaoglanidis, G. S. 2012. Biological activity of the succinate dehydrogenase inhibitor fluopyram against Botrytis cinerea and fungal baseline sensitivity. Pest Manage. Sci. 68:858-864.

Veloukas, T., Leroch, M., Hahn, M., and Karaoglanidis, G. S. 2011. Detection and molecular characterization of boscalid-resistant Botrytis cinerea isolates from strawberry. Plant Dis. 95:1302-1307.

Veloukas, T., Markoglou, A. N., and Karaoglanidis, G. S. 2013. Differential effect of $s d h B$ gene mutations on the sensitivity to SDHI fungicides in Botrytis cinerea. Plant Dis. 97:118-122.

Yanase, Y., Yoshikawa, Y., Kishi, J., and Katsuta, H. 2007. The history of complex II inhibitors and the discovery of penthiopyrad. Pages 295-303 in: Pesticide Chemistry: Crop Protection, Public Health, Environmental Safety. H. Ohkawa, H. Miyagawa, and W. L. Phillip, eds. WILEY-VCH, Weinheim, Germany.

Yin, Y. N., Kim, Y. K., and Xiao, C. L. 2011. Molecular characterization of boscalid resistance in field isolates of Botrytis cinerea from apple. Phytopathology 101:986-995.

Zhang, C. Q., Liu, Y. H., Ma, X. Y., Feng, Z., and Ma, Z. H. 2009. Characterization of sensitivity of Rhizoctonia solani, causing rice sheath blight, to mepronil and boscalid. Crop Prot. 28:381-386.

Zhang, C. Q., Yuan, S. K., Sun, H. Y., Qi, Z. Q., Zhou, M. G., and Zhu, G. N. 2007. Sensitivity of Botrytis cinerea from vegetable greenhouses to boscalid. Plant Pathol. 56:646-653. 